\title{
Tribological Behaviour of Neem Oil with and without Graphene Nanoplatelets Using Four-Ball Tester
}

\author{
B. Suresha $\mathbb{D}^{1},{ }^{1,2}$ G. Hemanth $\mathbb{D}^{1,},{ }^{1,2}$ Apurva Rakesh, ${ }^{1,2}$ and K. M. Adarsh ${ }^{1,2}$ \\ ${ }^{1}$ Department of Mechanical Engineering, The National Institute of Engineering, Mysore 570008, India \\ ${ }^{2}$ Visvesvaraya Technological University, Belagavi, Karnataka, India \\ Correspondence should be addressed to B. Suresha; sureshab2004@yahoo.co.in
}

Received 12 May 2019; Revised 16 August 2019; Accepted 25 October 2019; Published 25 January 2020

Academic Editor: Patrick De Baets

Copyright (c) 2020 B. Suresha et al. This is an open access article distributed under the Creative Commons Attribution License, which permits unrestricted use, distribution, and reproduction in any medium, provided the original work is properly cited.

\begin{abstract}
The present work was aimed to study the friction and wear behaviour of graphene nanoplatelets (GNPs) under extreme pressure conditions as an anti-weld additive for neem oil. The effect of neem oil, blended with various loading of GNPs on the friction and wear characteristics has been investigated. From the experimental results, it was found that $1 \mathrm{wt} . \%$ of GNPs in neem oil showed the least coefficient of friction and smoother wear scar diameter. The extreme pressure test was performed on neem oil with and without GNPs as per ASTM standards. The extreme pressure test results indicated the improvement in seizure load of neem oil by $27.8 \%$ at 0.5 wt. $\%$ of GNPs as compared to pure neem oil. Optical microscopy of worn steel ball surface revealed the pit formation and the formation of wedge cutting edge in GNPs modified neem oil.
\end{abstract}

\section{Introduction}

The friction and wear characteristics of machine components is a significant research area that is being thoroughly studied. A lubricant, apart from being used in automotive engines, finds its necessity in pneumatic circuits, food processing machinery, airplanes, hydraulic press and hydraulic jacks [1-3]. The operating conditions to which lubricants are exposed dictates its grade and shelf life. There are many researchers who worked to improve the properties of bio-based oils as lubricant and reduced the wear loss of machine elements $[4,5]$. Continuous efforts have been made to develop technology to avoid ill effects on the environment [6]. The rate of biodegradability of mineral oils is around $30-65 \%$ whereas, a bio-based oils is having almost 95\% [7]. Erhan et al. studied the lubricant base stock potential of chemically modified vegetable oils and concluded that the pollution problem is so severe that nearly $50 \%$ of all lubricants sold globally end up in the environment via volatility, spills, or total loss applications [8].

Owing to the ill effects of mineral and synthetic oils on the environment and human health and increasing oil demand and prices, the research objective was framed to pursue research on bio resources in the late 90 's and early $21^{\text {st }}$ century [9-11]. Regular efforts were made to substitute mineral oils with bio-based oils namely jatropha, spirulina, pongamia [12-14]. Friction and wear of tribo-system depend on various tribo parameters like applied normal load, sliding velocity, sliding distance and type of lubrication. Hsu et al. concluded that the effect of hydrodynamic condition of the lubricant does not have a significant effect on surface wear. However, the interaction between lubricant and surfaces in contact influence the tribological behaviour [15]. The bio-oils have a superior anti-corrosive property, high flash and fire point as well as feeble aquatic toxicity. Lubricants extracted from edible oil seeds pose severe food versus fuel issues that can be overcome by nonedible oils [16]. Many researchers have studied the friction and wear behaviour of bio-based oils [17-19]. The biooils comprise of triglycerol (molecular weight: $240.25 \mathrm{~g} / \mathrm{mol}$ ), and polar nature of the fatty acids allows it to form a bond with metallic surfaces and create a thin monolayer that is beneficial in reducing wear and friction $[18,19]$. The bio-based oils have few shortcomings, like poor thermal-oxidative stability, nonnegative pour point and gumming effect [20-23].

Incorporation of nanofillers into bio-oils has shown lower coefficient of friction and smoother wear scar diameter $[24,25]$. The reduction in wear loss was attributed to an increase in the viscosity of the base oil [24]. The viscosity enhancement was associated with the number of particles 
available per unit volume of oil. There are lot of parameters that dictate the behaviour of nanoparticles in the lubricant, some of which are size, geometry and chemical and physical properties. Nanoparticles tend to diffuse between two mating components thereby avoiding metal contacts leading to wear reduction. Some nano-additives form a bond with metal surfaces while some convert sliding into rolling friction [25-27]. Masuda et al. proved the incompatibility of metallic nanofillers with lubricant and concluded that surface activity was responsible for this incompatibility [28]. Not only the particulate additives play an important role in enhancing the tribological properties, but blending bio-based oils into lubricants also showed multi-functional behaviour [29-32]. Li et al. have demonstrated the application of natural garlic oil as a high performance and extreme pressure additive for lubricants [33]. Ossia et al. have acknowledged the presence of eicosanoic and octadecanoic acids in castor and jojoba oil and enhancing their oxidation stability and tribological properties [34]. Carbonaceous particles like soot, graphene, multiwalled carbon nanotube showed very good lubricity [35-37].

Neem is a native tree to Indian-subcontinent and is widely grown in Indian states namely, Uttar Pradesh, Tamil Nadu, and Karnataka. Its applications are discussed in ayurvedic literature. Schmutterer has analyzed the effect of neem derived products as pesticides [38]. There are a lot of works available dealing with applications of neem and their derivatives [3945]. Chaudhari et al. have discussed a self-healing coating of a polyurethane prepared from neem oil polyesteramides [46]. Muhammad et al. have discussed wear preventive characteristics of neem and Jatropha oil with antimony dialkyldithio carbonate [47]. Neem oil has promising benefits in all fields. However, neem oil was less explored with tribological properties as bio-lubricant. Hence, the present research work explores neem oil and the role of graphene nanoplatelets (GNPs) in neem oil on viscosity, friction and wear as well as on seizure load which are important factors that are accounted for the right selection of the appropriate lubricant in different sliding components of food processing machines. Hence, neem oil was preferred for the further conscientious investigation with and without graphene nanoplatelets.

\section{Materials and Methods}

Neem oil (NO) was procured from NIE-Center for Renewable Energy and Sustained Technology, Mysore, India. The Graphene nanoplatelets (GNPs) were procured from Sigma Aldrich, Bangalore, India. The specifications of GNPs are, surface area $750 \mathrm{~m}^{2} / \mathrm{g}$, the GNPs considered is structured out of 3-6 layers of $<50 \mathrm{~nm}$ thick. The density of the material is $0.2-0.4 \mathrm{~g} / \mathrm{cm}^{3}$. Figure 1 shows the Transmission Electron Microscopic image of GNPs obtained from product data sheet [48]. It can be observed from the TEM image that the GNPs are semi-transparent and they are in order of few nanometres.

2.1. Extraction of Neem Oil. The neem oil was produced from its seeds. The neem seeds were cleaned and crushed to extract oil out of it. The oil so obtained was filtered in two stages. Firstly, with a coarse filter of 180-micron mesh sieve and later

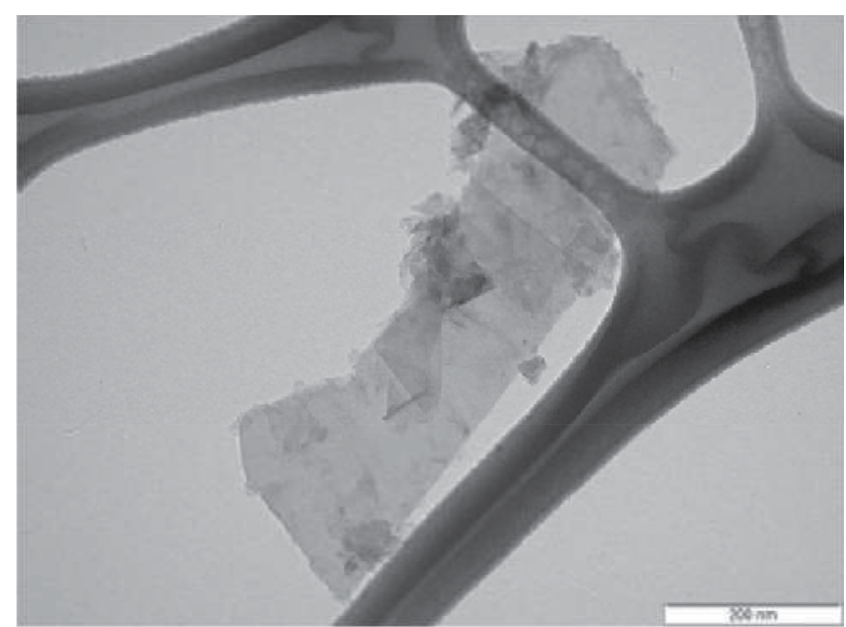

FIgURE 1: TEM image of GNPs [48].

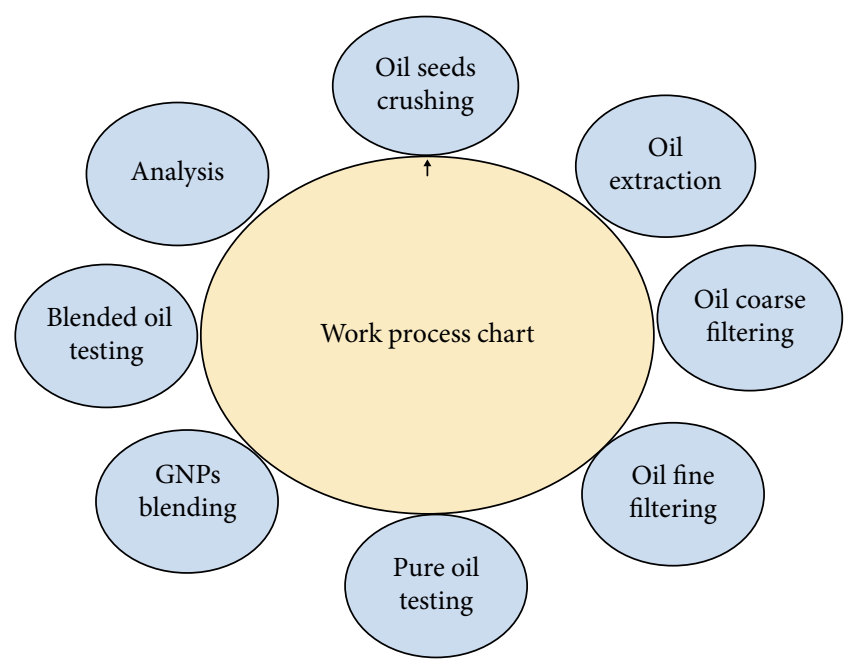

FIGURE 2: Work process chart of the current experimental work.

with 50-micron mesh sieve to remove finer impurities. Some of the particulate impurities were settled at the bottom of the container which was later discarded.

2.2. Blending Oil with Graphene Nanoplatelets. The neem oil obtained was thoroughly mixed with GNPs following ultrasonication. The loading of nanofillers has a great effect on the functionality of bio-oils as lubricants with about 0.1-1.5 wt.\% stated as the optimum loading for nanofillers in majority research works carried out [49-51]. Therefore, in the present work, for the purpose of evaluating the effect of GNPs loading on the tribological properties of neem oil, nanolubricants have been made at four different loadings viz., 0.25 , $0.5,0.75$, and $1.0 \mathrm{wt} . \%$ by incorporating GNPs to neem oil. The ultrasonication was performed for $15 \mathrm{~min}$ at a frequency of $22 \mathrm{kHz}$ using Johnson Ultrasonicator. Figure 2 shows the process chart of the current research.

2.3. Measurement of Kinematic Viscosity. The viscosity of the blended oils was tested along with bio-based oils. The 


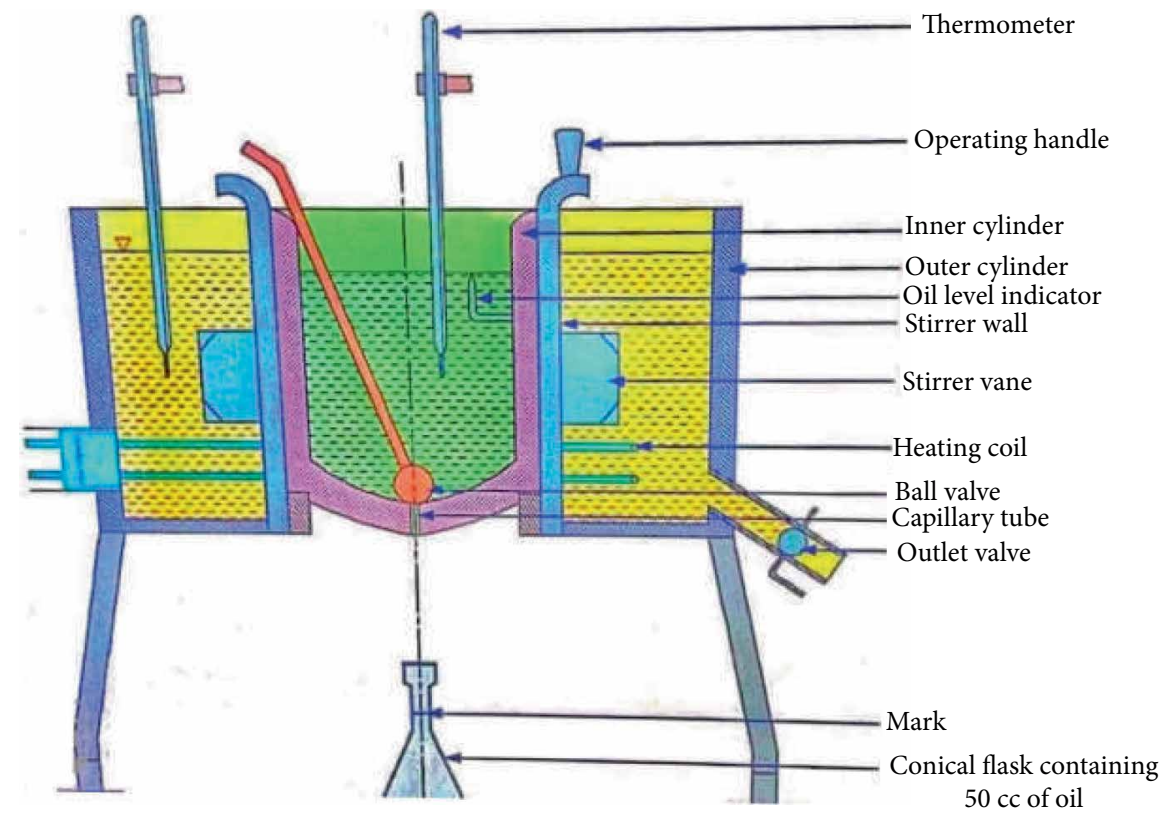

FIGURE 3: Sectional front view of the Redwood viscometer.

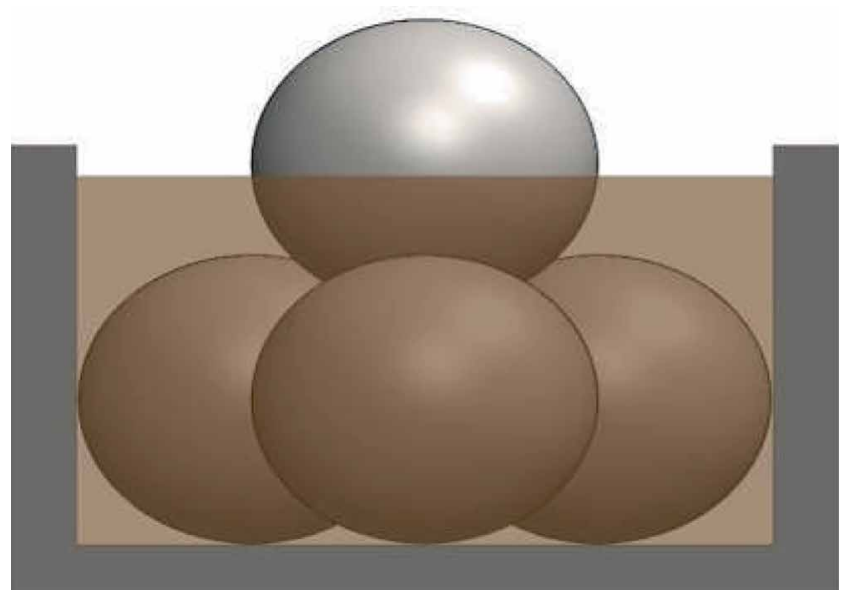

FIGURE 4: Schematic diagram of the four-ball tester.

viscosity test was carried on the redwood viscometer whose test procedure is governed by IP $70 / 62.50 \mathrm{~cm}^{3}$ of oil is allowed to flow down and corresponding flow time $(t)$ in seconds was recorded for further calculations. The orifice diameter of viscometer is $1.62 \mathrm{~mm}$. The test was initiated at $30^{\circ} \mathrm{C}$ and for every $5^{\circ} \mathrm{C}$ rise in temperature, the consecutive reading was noted. Five trials were done to affirm the values. Figure 3 shows the schematic representation of Redwood viscometer. Equation (1) was used to evaluate kinematic viscosity $(v)$.

$$
v=0.00247 \times t-\frac{0.65}{t} .
$$

2.4. Friction and Wear Test. The wear preventive characteristics of the NO-GNPs based lubricant were examined under fourball tribometer. The test procedure was governed by ASTM D 4172 [52]. The chromium steel balls of $12.7 \mathrm{~mm}$ diameter

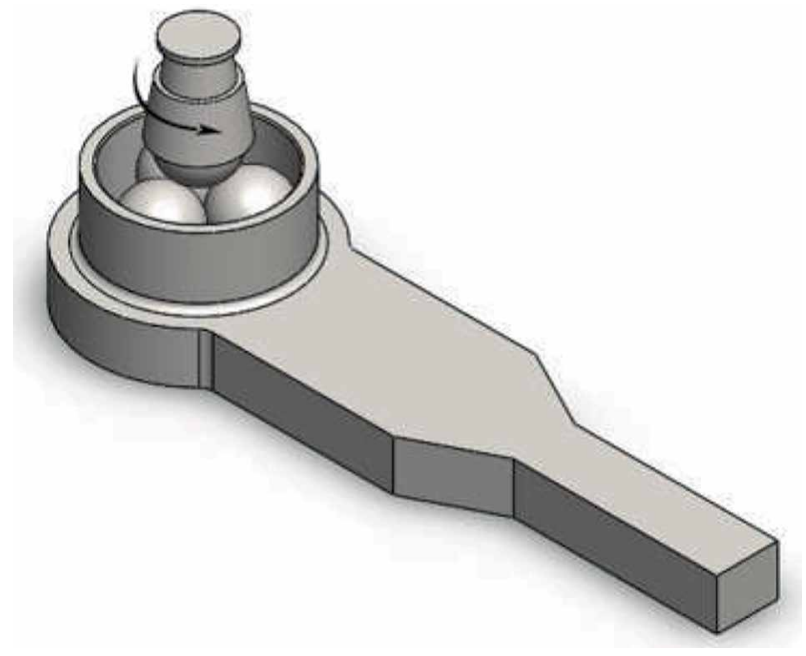

FIGURE 5: Assembly of four-ball tester with ball holder cup.

and 64-66 HRC with mirror polished surface was used for the investigation. The test duration was $60 \mathrm{~min}$, the temperature of the oil was $75^{\circ} \mathrm{C}$ and the rotation speed was kept $1200 \pm 1 \mathrm{rpm}$. The test load was maintained to be constant, which was $40 \pm 0.1 \mathrm{~kg}$. The coefficient of friction and wear scar diameter were obtained. Figures 4 and 5 depict the four-ball tester setup. Seizure load is the lowest applied load at which the rotating ball weld to the stationery balls indicating extreme pressure level of the lubricants. The extreme pressure test was performed according to ASTM D2783 standard [53]. The test conditions were as follows, the load was varied from $400 \mathrm{~N}$ till the seizure load with an increment of $100 \mathrm{~N}$, speed was maintained to be $1760 \pm 30 \mathrm{rpm}$, oil temperature was $25^{\circ} \mathrm{C}$ and the duration of the test was $10 \mathrm{~s}$. Once the seizure occurs, to find the seizure load precisely, the load was decreased by $10 \mathrm{~N}$ for each trial 
TABLE 1: Kinematic viscosity of various wt.\% of GNPs-neem nano-lubricants.

\begin{tabular}{lcc}
\hline $\begin{array}{l}\text { Nano-lubricant } \\
\text { formulations }\end{array}$ & Designation & $\begin{array}{c}\text { Kinematic viscosity } \\
\text { at } 40^{\circ} \mathrm{C}\left(\mathrm{mm}^{2} / \mathrm{s}\right)\end{array}$ \\
\hline $\begin{array}{l}\text { Pure neem oil } \\
\text { Neem oil mixed with }\end{array}$ & NO & $53.3 \pm 0.35$ \\
$\begin{array}{l}0.25 \text { wt.\% GNPs } \\
\text { Neem oil mixed with }\end{array}$ & $0.50 \%$ GNPs-NO & $58.5 \pm 0.61$ \\
$\begin{array}{l}\text { 0.50 wt.\% GNPs } \\
\text { Neem oil mixed with }\end{array}$ & $0.75 \%$ GNPs-NO & $62.3 \pm 0.53$ \\
$\begin{array}{l}0.75 \text { wt.\% GNPs } \\
\text { Neem oil mixed with } \\
1.0 \text { wt.\% GNPs }\end{array}$ & $1.0 \%$ GNPs-NO & $67.193 \pm 0.4$ \\
\hline
\end{tabular}

until the seizure load was obtained. Five trials were performed as mentioned above to affirm the values.

\section{Results and Discussion}

3.1. Effect of GNPs Loading on Viscosity of Neem Oil. The rate of fluid resistance against its flow is called viscosity, which is one of the vital factors for selecting proper lubricating oil for moving components in machinery. Since, one of the important properties of a lubricant is the viscosity, in the present research work; the focus is on the effect of loading of GNPs into the neem oil which results in change of viscosity. For this reason, the viscosity of the lubricating oil which did not contain nanoparticles was considered as a base fluid (neem oil) and also the viscosity of the bio-lubricants which contain GNPs at four loadings $0.25,0.5 .0 .75$, and $1.0 \mathrm{wt} . \%$ and with an increase in temperature from $30^{\circ} \mathrm{C}$ to $55^{\circ} \mathrm{C}$ was measured. The experimental results are summarized in Table 1 and are also shown in Figure 6. It can be seen, the viscosity of GNPs-NO nano-lubricants the temperatures had increased from $30^{\circ} \mathrm{C}$ to $55^{\circ} \mathrm{C}$ by increasing the loading of GNPs, although the rate of change in viscosity at lower loadings was much smaller than that at higher loadings.

The stimulating point related to the amplified viscosity of GNPs-NO nano-lubricants with $1.0 \mathrm{wt}$ \% loading is that, for increasing temperatures, the viscosity of neem oil without GNPs had a substantial decrease. When GNPs were incorporated to the neem oil, they were positioned between the neem oil layers and escort to ease the fluid layer movement on each other. As a result, the viscosity decreased slightly and the decreasing trend can be seen for $0.25 \%$ and $0.5 \%$ GNPs-NO nano-lubricants as shown in Figure 6. As GNPs loading increases, nanofillers agglomerate and create bigger and asymmetric particles, which prevent movement of fluid layers on each other; hence the viscosity increased for higher loadings (0.75 and 1.0 wt.\%) of GNPs-NO nano-lubricants. The same behaviour was observed by other researchers with different liquids and nano additives [54-57]. Wang et al. observed about $86 \%$ improvement in the viscosity of distilled water on incorporation of $\mathrm{Al}_{2} \mathrm{O}_{3}[54]$.

3.2. Wear Preventive Characteristics GNPs Modified Neem

Oil. The wear preventive characteristics were first conducted

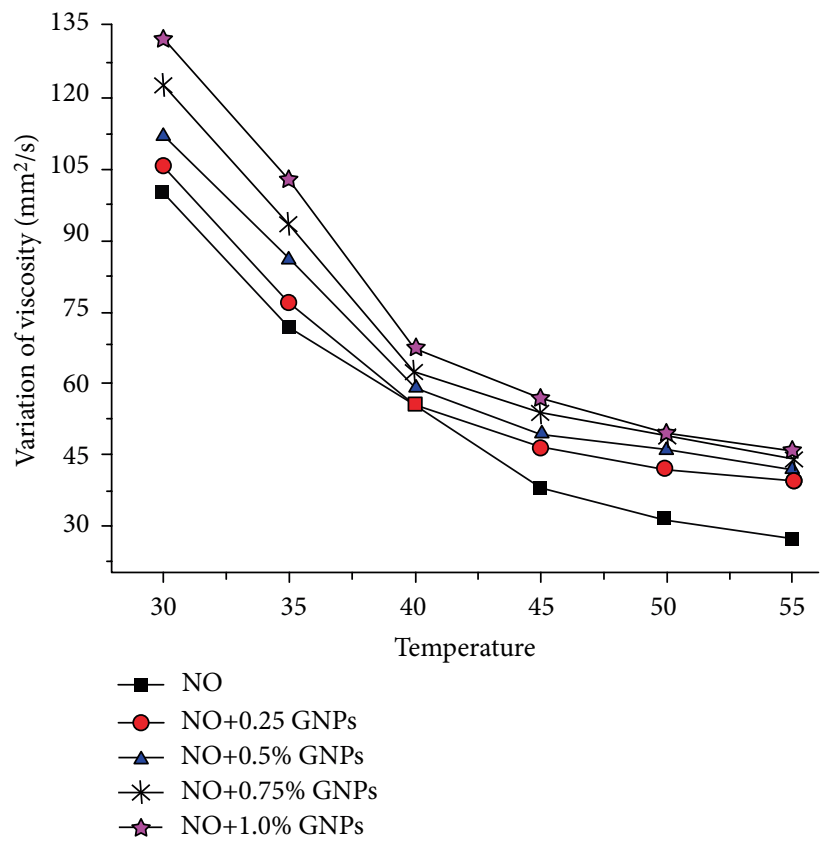

FIGURE 6: Kinematic viscosity of GNPs-neem nano-lubricants.

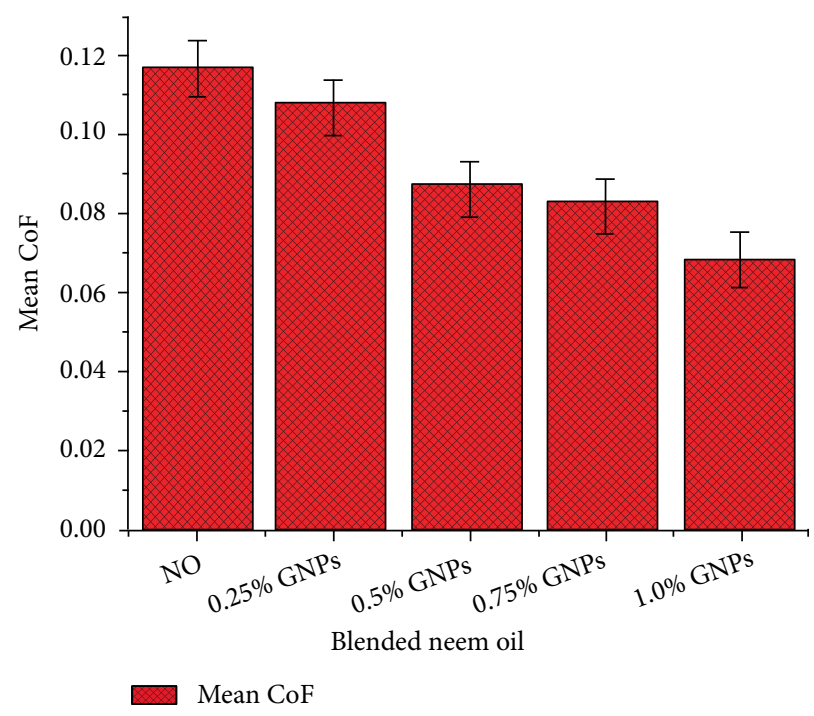

FIGURE 7: Mean coefficient of friction of GNPs-neem nano-lubricants.

on pure NO and then followed by blended oils of NO. There are many factors that influence lubricant properties. In this regard, the coefficient of friction versus oil combinations plot is as shown in Figure 7. It was seen that the coefficient of friction was reduced by $7.5 \%$ on incorporation of $0.25 \%$ GNPs-NO, $25.2 \%$ with $0.5 \%$ GNPs-NO, $28.9 \%$ with $0.75 \%$ GNPs-NO and the highest reduction was found with $1.0 \%$ GNPs-NO which was around $41.4 \%$ with the base NO. A significant reduction of $23 \%$ was observed in wear scar diameter with $1.0 \%$ GNPs-NO in relation to unblended NO. This reduction can be associated with an increment in the viscosity of the oil which helped in the formation of thin-film owing to the decrease in wear scar diameter as well. 


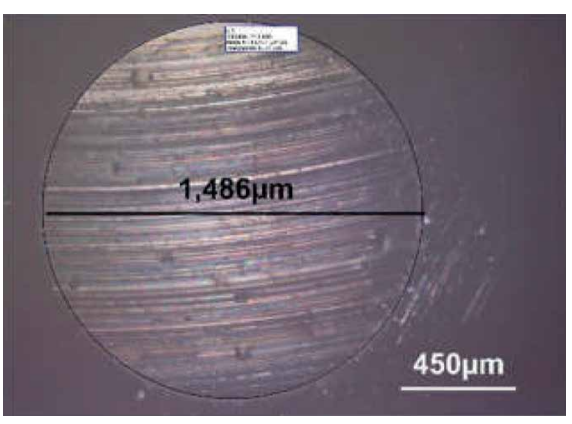

(a)

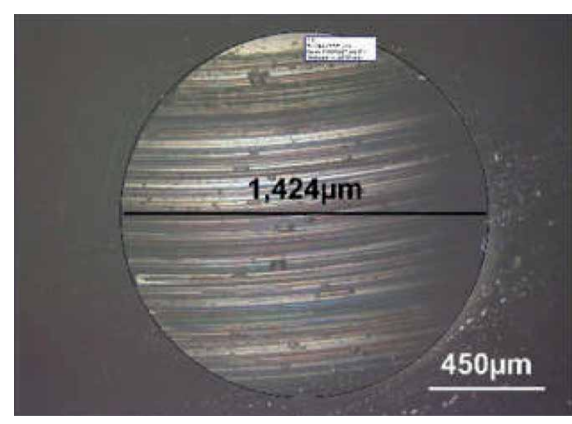

(b)

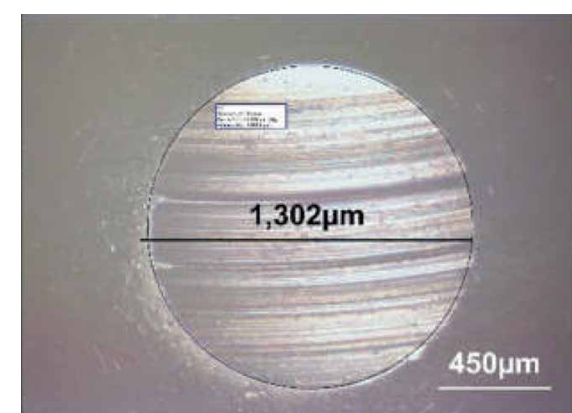

(c)

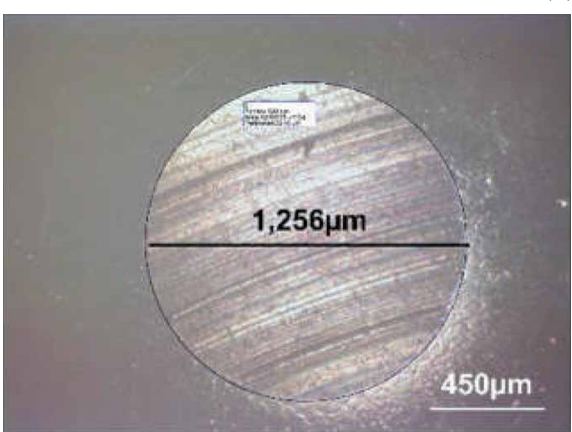

(d)

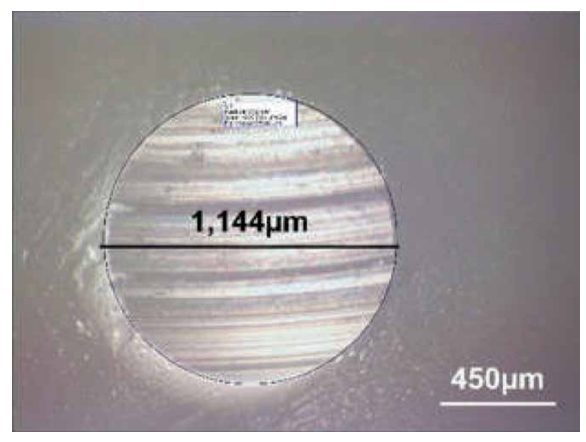

(e)

Figure 8: Optical micrographs of wear scar diameter: (a) pure neem oil, (b) 0.25\% GNPs-NO, (c) 0.50\% GNPs-NO, (d) 0.75\% GNPs-NO, and (e) $1.0 \%$ GNPs-NO.

From Figure 8, it can be observed that GNPs modified oil with lower percentages of GNPs showed darker concentric grooves which depict abrasive wear whereas in higher percentages of GNPs it showed smoother wear track depicting reduced contact between steel balls. The darker grooves are deeper whereas brighter grooves are shallow. A similar observation was found by Suresha et al. [58]. It is these grooves that are responsible for holding GNPs back on the wear surface causing reduction in wear, the same phenomenon was discussed by Huang et al. where they have incorporated graphite sheets [59]. Hernandez et al. have proved experimentally that nanoparticle will accumulate in the wear scar region [60].

The load is the primary characteristics that affect wear. Ing et al. proved that variations in the load largely dictates the wear on the surface of the steel balls [61]. The chemical composition of the lubricant oil affects the wear preventive characteristics. Stachowiak and Batchelor have discussed that synthetically produced lubricants have compounds containing phosphides and sulphide ions that have a tendency to react with the surface of the steel balls which prevent the metallic contact to a certain extent and reduce the wear [62]. However, the sulphide and phosphide compounds are not present in bio-based resources which makes the bio-based resources to have higher wear scar than mineral or synthetic oils [61]. The reason for improvement in anti-frictional properties was the enhancement in viscosity whereas, improvement in anti-wear property was due to the uniformity in the dispersion of GNPs. The quintessential proof for the latter condition can be found in the work of Hu et al. [63].

\subsection{Effect of GNPs Modified Neem Oil on Extreme Pressure}

Characteristics. The extreme pressure test was started with NO to seek for their seizure load followed by the blended oils. The

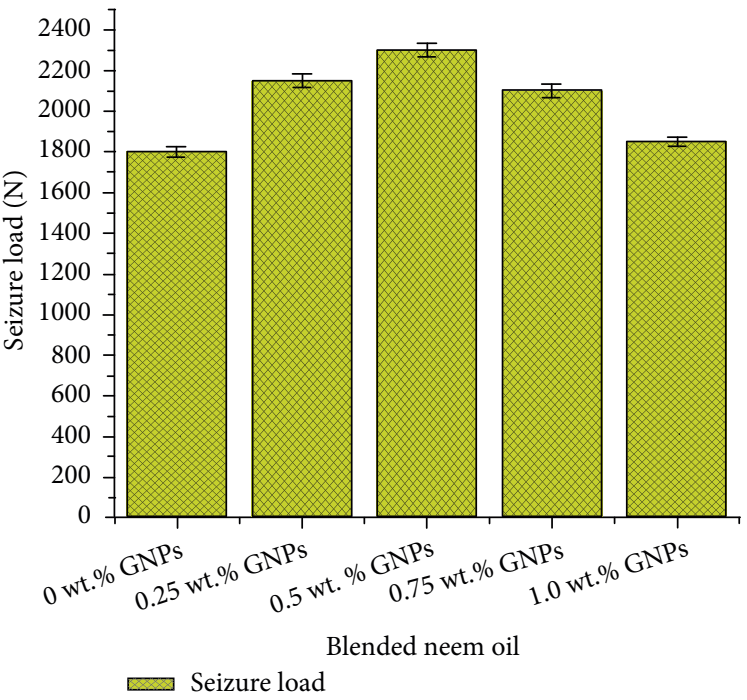

FIGURE 9: Seizure load of various wt.\% of GNPs-neem nanolubricants.

GNPs blended into oil helps to sustain the failure by enhancing the seizure load. It was observed in Figure 9 that the seizure load was found to be increased with all combinations of GNPs blend. Among all combinations of oils 0.5\% GNPs-NO has portrayed the outstanding improvement in seizure load of $2300 \mathrm{~N}$ owing to $27.7 \%$ increment in seizure load in accordance with NO. However, the higher percentages of GNPs modified NO did not show further increment in seizure load.

The reason that can be attributed to this increment in seizure load is the viscosity of the unblended and blended neem oil. Binu 


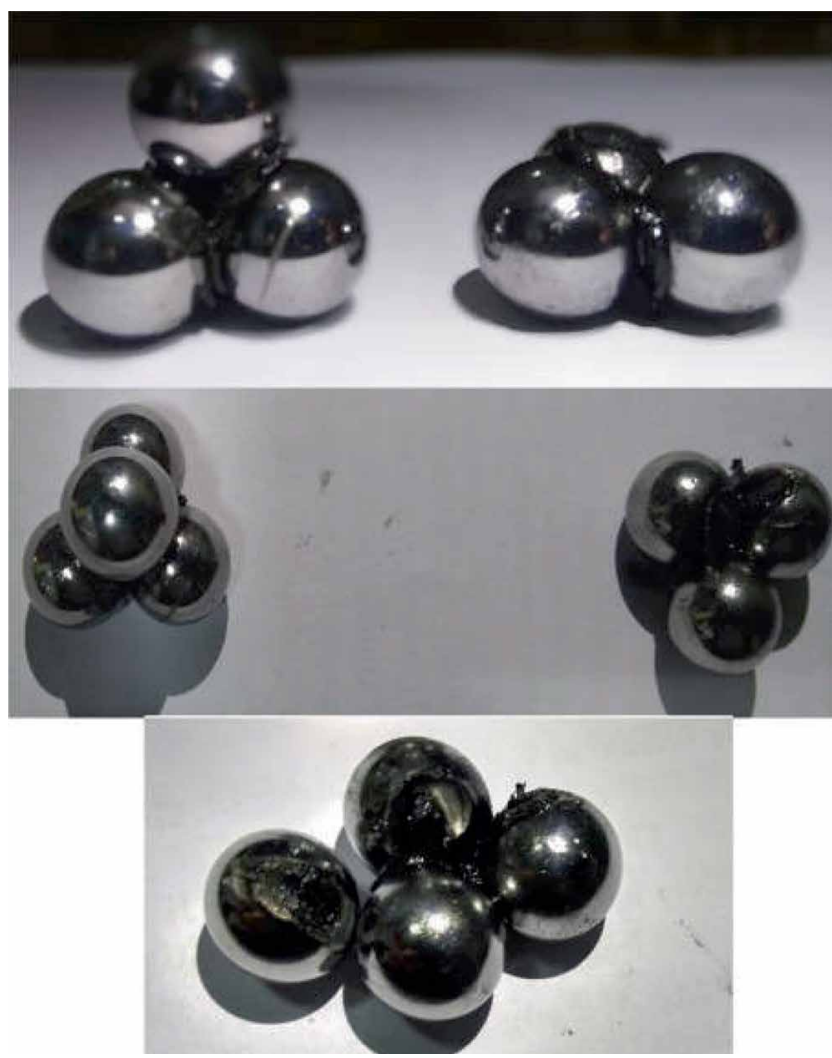

FIGURE 10: Steel balls after extreme pressure test at the seizure load.

et al. have discussed the relation between the viscosity and loadcarrying capacity by using different models and experimental validation [64]. There is a correlation between the minimum oil film thickness and viscosity [65]. The viscosity improves load carrying capacity [66]. Hence, it can be said that the thickness of oil film generated controls maximum load on the component. Though the increment in viscosity was high with $1.0 \%$ GNPs-NO the seizure load was lesser than $0.5 \%$ GNPs-NO.

Kozma had worked and concluded about the relation between the scuffing load and viscosity, continuing and further noticed that with increment in viscosity, scuffing load increased up to a certain extent and then remained constant with an increase in viscosity [67]. However, there is a limitation to the extent to which nanoparticles can be blended with liquid, beyond which the improved performance ceases to prevail [49-51]. Figure 10 shows the steel balls after the extreme pressure test. At the seizure load, the thickness of the film reduces making the lubrication fall in thin-film lubrication regime. This thin film gets the surfaces in contact leading to abrasion. During abrasion, cooling effect of lubricant failed which led to a rise in temperature to higher value. Melting the steel balls and joining them. Metal squeeze out can also be observed at the interface.

3.4. Wear Mechanism in Extreme Pressure Characteristics. The wear behaviour under extreme loading conditions was studied. The formation of a thin film between two balls was responsible for high seizure load of NO at higher loads as shown in Figure 11(a). Blok has discussed that there will the surface irregularities which form an interlocking, that tends to reduce in the surface area of the mating when compared to the apparent area. This reduction in the area causes a very high bearing pressure that tends to form strain hardening [68].

This was avoided by the formation of the thin film that avoided the steel balls getting in contact with each other and prevented them from getting worn out. Thin-film formation just before seizure load with $0.5 \%$ GNPs-NO and $1.0 \%$ GNPs-NO are shown in Figures 11(b) and 11(c). The film thickness was shown varied because of exposure to the oil film to the same load. Viscosity plays a major role leading to the formation of the thin film. The wear mechanism after blending GNPs with NO is unlike to the condition without GNPs. Upon increase in viscosity, lubricant film formed will have a higher thickness that will avoid the steel balls getting into contact with each other, if the film thickness increases, the gap between friction surfaces increases eventually reducing the wear. To get steel balls in contact with each other, lubricant film destruction is necessary. To destroy lubricant film requires more load. Thereby, it increases the seizure load. Just before the seizure, the film thickness was very less, then the minuscule GNPs will diffuse between the balls and some GNPs were stopped by the wear scar formed. Hence, they settle in the wear scar region, over which the balls slide. GNPs being multilayered, experiences a shear force and avoids the metallic contact thereby further increasing the seizure load by a small amount.

After certain loading, the thin film fails to form leading the metal surfaces to contact. This contact region was the high thermal zone leading to the melting of steel at the point of contact. Syahrullail et al. found that during extreme pressure on vegetable oils the wedge cutting edges will be formed due to high load [69]. In the present study, the wear scar was observed under an optical microscope and abrasive wear was predominantly noticed. $\mathrm{Xu}$ et al. proved that the graphene adheres to the wear scar which acts as a solid lubricant and sustains the high load up to a certain level [70].

Figure 12 shows shearing of GNPs when exposed to a very high load and high speed of operation. The amount of GNPs $(0.25 \%$ and $0.5 \%)$ present in the neem oil was better in reducing coefficient of friction and wear resistance, similar to that described by Xu et al. [70]. Abrasive wear occurs because of the presence of more amount of GNPs in a unit volume of oil considered. Hence, this abrasive action of GNPs removed the material from steel balls. The material removal was associated with high-temperature generation due to the metallic contact, which in turn causes the seizure by joining the steel balls. Zhang et al. investigated with oleic acid-modified graphene, at 5 wt.\% showed abrasive wear behaviour [71]. Hernandez et al. have also discussed that the concentration of nanoparticles accumulated at wear scar region will vary and will be more than the concentration of nanoparticles in the lubricant [60]. There is one more reason which also has some critical influence on seizure load that is aggregates of GNPs bigger than thin film formed by the liquid which can not diffuse in between the steel balls paving a way to more wear and instant weld [72].

3.5. Metallurgical Aspects Involved in Welding of Balls. It was required to focus the effect of the high load abrasive wear on the metallurgical parameters and metallurgical modifications 


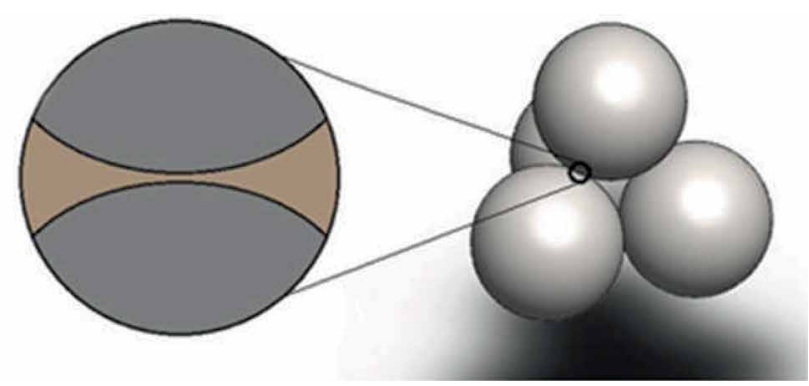

(a)

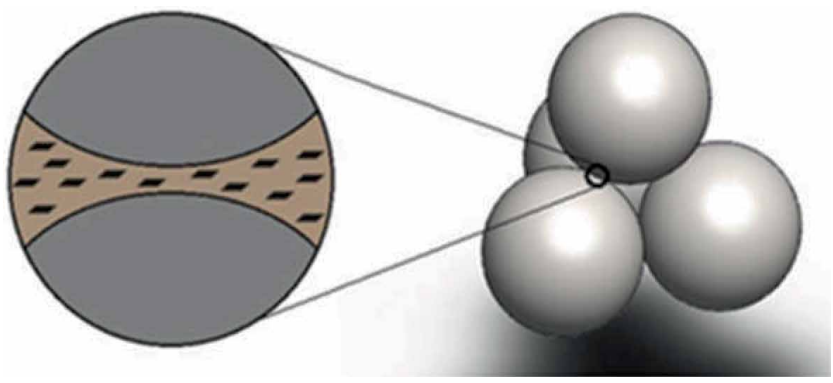

(b)

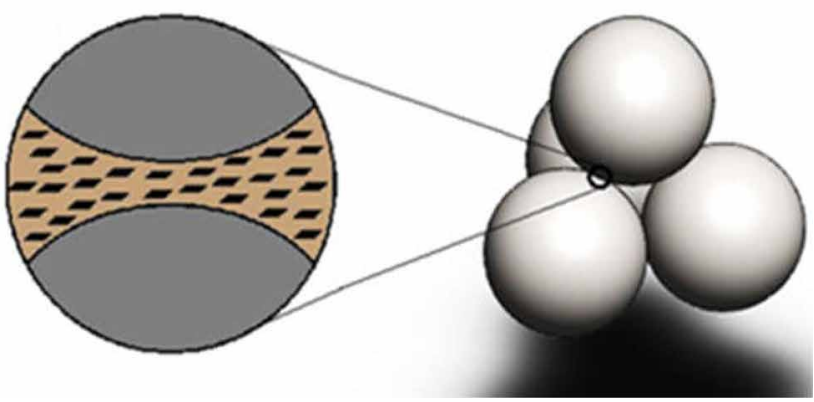

(c)

Figure 11: Illustration of formation of thin-film between balls just before the weld: (a) 0.25 wt.\% GNPs-NO, (b) $0.50 \%$ GNPs-NO, and (c) $1.0 \%$ GNPs-NO.
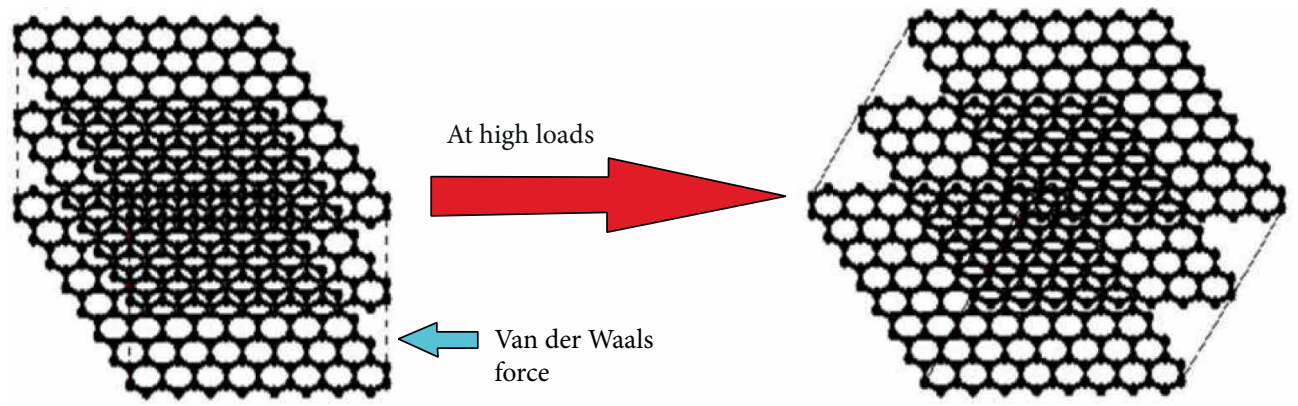

FIGURE 12: Illustration of shearing of GNPs at high load $(2300 \mathrm{~N})$ for 1.0\% GNPs-NO.

that occur in steel balls. In this regard, Ming Feng has discussed that the metallic surface in contact and in relative motion with each other forms grooves and the ridges. Consequently, this formation is followed by strain hardening. It was also mentioned that there will be debris formation or shear that takes place that raises the temperature to such an extent that is sufficient to melt the steel balls at the contact point and stick it to one of the mating surfaces [73].

Similar to the conditions discussed by Syahrullail et al., Figure 13(a) shows the wedge cutting edges found in case of neem oil [69]. The wedge cutting edge was formed due to the high load and high speed of operation which further led to 


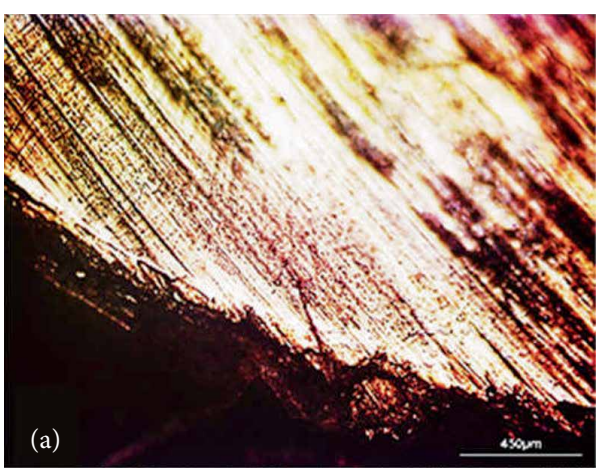

(a)

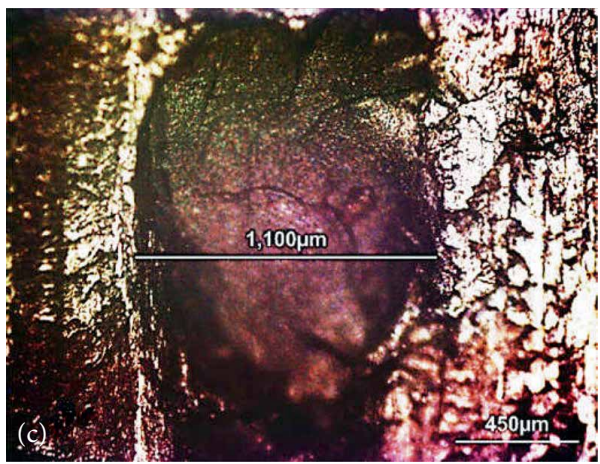

(c)

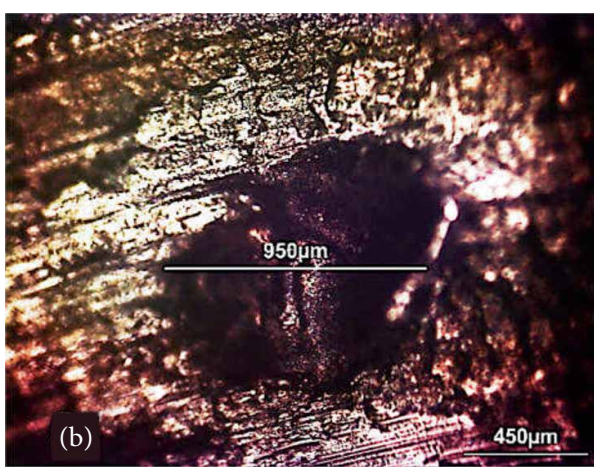

(b)

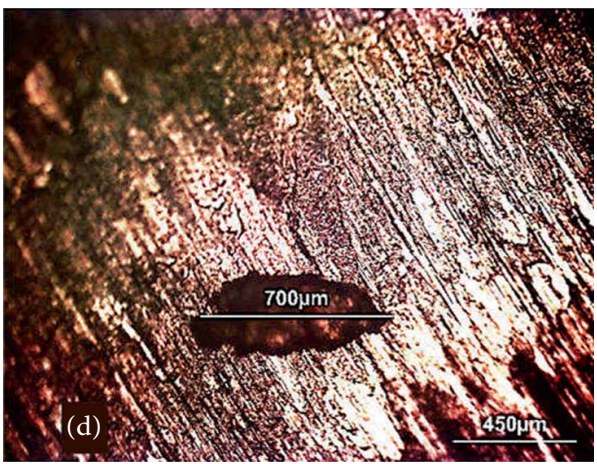

(d)

FIGURE 13: Optical micrographs showing wedge cutting edge and pit formation: (a) wedge cutting edge in NO, (b) Pit in Pure NO, (c) 0.25\% GNPs-NO, and (d) 0.5\% GNPs-NO.

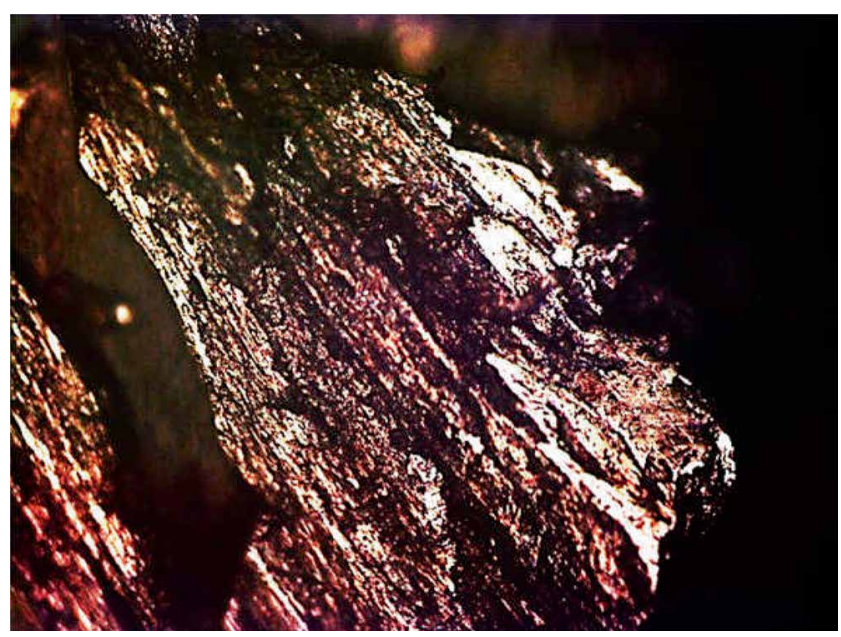

Figure 14: Metal squeeze out due to high load $(2300 \mathrm{~N})$ 0.5\% GNPs-NO.

high temperature and caused the metal to melt. However, the edges were exposed to the very high thermal atmosphere caused a partial seizure that indicated the approaching weld point. At the point of contact due to the abrasion effect, the temperature was increased and eventually seized the balls.

It was observed that the balls were exposed to a very high load of order $2.3 \mathrm{kN}$ and high operational speed the balls started welding and de-welding which in turn caused the -joining of steel balls. Abrasion wear action further leads to the micro joint of the metal from stationery balls to its counterpart.
In this study, the above-mentioned case can be clearly observed in Figures 13(b)-13(d). Wear phenomenon forms a pit on the ball surface while examining. As evidence, pits were observed in optical microscope image taken from the optical microscope coupled with the Four-ball tribometer. Zulkifli et al. have discussed that the steel balls form a micro joint with each other and this micro joint when ruptured forms a pit [74]. In Figure 13 , when compared to NO and $0.25 \%$ GNPs-NO, wear pit observed with $0.5 \%$ GNPs-NO was lesser as observed in Figure 13(d) because at such a high load the metal will squeeze out to the edges forming the wedge cutting edge rather than adhering on to the rotating ball surface. This phenomenon can be visualized in Figure 13(a). However, the formation of pits seem to be more significant in the NO and $0.25 \%$ GNPs-NO.

Figure 14 depicts the bulk matter squeezed out from the edges due to melting of balls operated under high load of $2300 \mathrm{~N}$. The noteworthy reason is that due to very high load, a temperature gradient was observed in steel balls at the point of contact and this temperature gradient decreases the hardness value, in turn causing metal to melt. The squeeze-out in the case of $0.5 \%$ GNPs-NO is shown in Figure 14.

\section{Conclusions}

The current investigation presented the possible enhancement of the viscosity, wear preventive and extreme pressure characteristics of neem oil via the inclusion of $0.25-1.0 \%$ GNPs-NO. GNPs were around $<50 \mathrm{~nm}$, flake form and very much 
scattered, utilizing ultrasonication in the neem oil as a base lubricant. On the basis of results presented in the preceding section, the following conclusions can be drawn:

(i) The viscosity of pure neem oil curtailed as for temperature and augmented with respect to the GNPs loading (0.25-1.0 wt.\%) for the temperature range of $30^{\circ} \mathrm{C}-55^{\circ} \mathrm{C}$ of the examination.

(ii) The tribological examination of neem oil with low filler loading of graphene nanoplatelets (GNPs) as additives particularly 1.0\% GNPs-NO indicated a huge decrease in the friction coefficient and wear scar diameter. This could be because of the better dispersibility of GNPs in neem oil as these nanoparticles offer better anti-wear ability.

(iii) Tribological testing demonstrates that the utilization of GNPs is effective for the decrease of coefficient of friction and wear with expanding loading of GNPs. The utilization of higher loaded GNPs (1.0 wt.\%) is more compelling than the utilization of pure neem oil. Likewise, the capacity of nano-lubricant for friction and wear reduction depended not just on the concentration of nanoparticles included and tribological behaviour of the nanoparticles, yet in addition to the dispersion pattern of nanoparticles in the neem oil (uniformity of dispersion).

(iv) The patterns of the varying coefficient of friction demonstrate that friction and wear reducing graphene nanolayer forms amid the tribo-testing.

(v) The surface roughness of the steel ball improved with an increase in the loading of GNPs. Optical micrographs of the wear spots indicate a smooth surface, diminished wear scar diameter with the nanoparticles adhered to the contact surface during the wear test of the neem oil with GNPs. The distinctive structure of the formed friction surface was clearly seen in the contact zone and over the remainder of the ball surface.

(vi) Incorporation of GNPs into neem oil brought about an increase of the load-carrying capacity of the bio-lubricant up to $27.7 \%$ with $0.5 \%$ GNPs-NO. However, the seizure load was expanded by $2.8 \%$ with $1.0 \%$ GNPs-NO loading. This could be expected to their tribo-sintering onto the surfaces and their spacer impact because of their larger surface area and the formation of a thin graphene layer on the ball surface.

\section{Data Availability}

Previously reported data were used to support this study. These prior studies (and datasets) are cited at relevant places within the text as references.

\section{Conflicts of Interest}

The authors declare that there are no such conflicts of interest regarding the publication of this paper.

\section{Acknowledgments}

This work was funded by The National Institute of Engineering, Centre for Research \& Development (NIE-CRD) and TEQIPIII, NPIU. The authors would like to acknowledge the support of the Board of Management, NIE, Principal Dr. G. Ravi, and TEQIP-III Coordinator Dr. B.N. Yuvaraju. The tribometer was procured from Magnum Engineers, Bangalore, India we would like to extend our sincere gratitude to Magnum Engineers. We are also grateful to Ms. Chaitra Ramesh, Assistant Professor, NIE, who moderated this paper and in that line improved the manuscript significantly. Thanks go to the following Centre for Composite Materials Research (CCMR), NIE, technical staff Mr. Byresh and Mr. M. Madhusudhan for the help rendered in conducting experiments.

\section{References}

[1] M. R. Hilton and P. D. Fleischauer, "Applications of solid lubricant films in spacecraft," Surface and Coatings Technology, vol. 54, pp. 435-441, 1992.

[2] F. Zhou, Y. Liang, and W. Liu, "Ionic liquid lubricants: designed chemistry for engineering applications," Chemical Society Reviews, vol. 38, pp. 2590-2599, 2009.

[3] D. Klamann, R. R. Rost, and A. Killer, "Lubricants and related products: synthesis, properties, applications," International Standards, Verlag Chemie, Weinheim, 1984.

[4] O. Beeck, J. W. Givens, and E. C. Williams, "On the mechanism of boundary lubrication. II. Wear prevention by addition agents," Proceedings of the Royal Society of London. Series A. Mathematical and Physical Sciences, vol. 177, no. 968, pp. 103-118, 1940.

[5] D. B. Asay, M. T. Dugger, J. A. Ohlhausen, and S. H. Kim, "Macro-to nanoscale wear prevention via molecular adsorption," Langmuir, vol. 24, no. 1, pp. 155-159, 2008.

[6] M. M. El-Halwagi, Pollution Prevention Through Process Integration: Systematic Design Tools, Elsevier, 1997.

[7] W. J. Bartz, "Ecotribology: environmentally acceptable tribological practices," Tribology International, vol. 39, no. 8, pp. 728-733, 2006.

[8] S. Z. Erhan, B. K. Sharma, Z. Liu, and A. Adhvaryu, "Lubricant base stock potential of chemically modified vegetable oils," Journal of Agricultural and Food Chemistry, vol. 56, no. 19, pp. 8919-8925, 2008.

[9] R. M. Rowell and J. Rowell, Paper and Composites From AgroBased Resources, CRC Press, 1996.

[10] A. Sorrentino, G. Gorrasi, and V. Vittoria, "Potential perspectives of bio-nanocomposites for food packaging applications," Trends in Food Science \& Technology, vol. 18, no. 2, pp. 84-95, 2007.

[11] E. Munch, M. E. Launey, D. H. Alsem, E. Saiz, A. P. Tomsia, and R. O. Ritchie, “Tough, bio-inspired hybrid materials," Science, vol. 322, no. 5907, pp. 1516-1520, 2008.

[12] N. Talib, R. M. Nasir, and E. A. Rahim, “Tribological behaviour of modified jatropha oil by mixing hexagonal boron nitride nanoparticles as a bio-based lubricant for machining processes," Journal of Cleaner Production, vol. 147, pp. 360-378, 2017.

[13] Y. Xu, X. Hu, K. Yuan, G. Zhu, and W. Wang, "Friction and wear behaviors of catalytic methylesterified bio-oil," Tribology International, vol. 71, pp. 168-174, 2014. 
[14] R. Thanigaiselvan, T. S. Raja, and R. Karthik, "Investigations on eco-friendly insulating fluids from rapeseed and Pongamia pinnata oils for power transformer applications," Journal of Electrical Engineering and Technology, vol. 10, no. 6, pp. 2348-2355, 2015.

[15] S. M. Hsu, R. Munro, and M. C. Shen, "Wear in boundary lubrication," Proceedings of the Institution of Mechanical Engineers, Part J: Journal of Engineering Tribology, vol. 216, no. 6, pp. 427-441, 2002.

[16] M. M. Gui, K. T. Lee, and S. Bhatia, "Feasibility of edible oil vs. nonedible oil vs. waste edible oil as biodiesel feedstock," Energy, vol. 33, no. 11, pp. 1646-1653, 2008.

[17] A. Aravind, M. L. Joy, and K. P. Nair, "Lubricant properties of biodegradable rubber tree seed (Hevea brasiliensis Muell. Arg) oil," Industrial Crops and Products, vol. 74, pp. 14-19, 2015.

[18] N. J. Fox, B. Tyrer, and G. W. Stachowiak, "Boundary lubrication performance of free fatty acids in sunflower oil," Tribology Letters, vol. 16, no. 4, pp. 275-281, 2004.

[19] A. Adhvaryu, G. Biresaw, B. K. Sharma, and S. Z. Erhan, "Friction behaviour of some seed oils: biobased lubricant applications," Industrial \& Engineering Chemistry Research, vol. 45, no. 10, pp. 3735-3740, 2006.

[20] M. Mofijur, H. H. Masjuki, M. A. Kalam, M. Shahabuddin, M. A. Hazrat, and Liaquat, A.M., "Palm oil methyl ester and its emulsions effect on lubricant performance and engine components wear," Energy Procedia, vol. 14, pp. 1748-1753, 2012.

[21] N. Ponnekanti and S. Kaul, "Development of eco-friendly /biodegradable lubricants: an overview," Renewable and Sustainable Energy Reviews, vol. 16, no. 1, pp. 764-774, 2012.

[22] H.-S. Hwang and S. Erhan, "Modification of epoxidized soybean oil for lubricant formulations with improved oxidative stability and low pour point," Journal of American Oil and Chemical Society, vol. 78, pp. 1179-1184, 2001.

[23] Z. He, J. Lu, X. Zeng et al., "Study of the tribological behaviors of S, P-containing triazine derivatives as additives in rapeseed oil," Wear, vol. 257, no. 3-4, pp. 389-394, 2004.

[24] H. Sato, N. Tokuoka, H. Yamamoto, and M. Sasaki, "Study on wear mechanism by soot contaminated in engine oil (first report: relation between characteristics of used oil and wear)," SAE Technical Paper, 1999.

[25] Y. Y. Wu, W. C. Tsui, and T. C. Liu, "Experimental analysis of tribological properties of lubricating oils with nanoparticle additives," Wear, vol. 262, no. 7-8, pp. 819-825, 2007.

[26] L. Y. Yu, C. C. Hao, L. N. Sui, and Z. L. Cui, "Study on improving the friction and wear properties of lubricating oil with nanoparticles," Cailiao Kexue yu Gongcheng Material Science and Engineering, vol. 22, no. 6, pp. 901-905, 2004.

[27] Y. L. Qiao, X. F. Sun, B. S. Xu, and S. N. Ma, "High temperature tribological behaviours of nano-diamond as oil additive," Journal of Central South University of Technology, vol. 12, no. 2, pp. 181-185, 2005.

[28] H. Masuda, A. Ebata, and K. Teramae, "Alteration of thermal conductivity and viscosity of liquid by dispersing ultrafine particles. Dispersion of $\mathrm{Al}_{2} \mathrm{O}_{3}, \mathrm{SiO}_{2}$ and $\mathrm{TiO}_{2}$ ultra-fine particles," Netsu Bussei, vol. 7, no. 4, pp. 227-233, 1993.

[29] G. Karmakar and P. Ghosh, "Soybean oil as a biocompatible multifunctional additive for lubricating oil," ACS Sustainable Chemistry and Engineering, vol. 3, no. 1, pp. 19-25, 2015.
[30] P. Ghosh and G. Karmakar, "Evaluation of sunflower oil as a multifunctional lubricating oil additive," International Journal of Industrial Chemistry, vol. 5, no. 1, 2014.

[31] G. Karmakar and P. Ghosh, "Green additives for lubricating oil," ACS Sustainable Chemistry and Engineering, vol. 1, pp. 1364-1370, 2013.

[32] P. Ghosh, M. Hoque, and G. Karmakar, "Castor oil as potential multifunctional additive in the formulation of eco-friendly lubricant," Polymer Bulletin, vol. 75, no. 2, pp. 501-514, 2017.

[33] W. Li, C. Jiang, M. Chao, and X. Wang, "natural garlic oil as a high-performance, environmentally friendly, extreme pressure additive in lubricating oils," ACS Sustainable Chemistry and Engineering, vol. 2, no. 4, pp. 798-803, 2014.

[34] C. V. Ossia, H. G. Han, and H. Kong, "Additive properties of saturated very long chain fatty acids in castor and jojoba oils," Journal of Mechanical Science and Technology, vol. 22, pp. 1527-1536, 2008.

[35] E. Hu, X. Hu, T. Liu, L. Fang, K. D. Dearn, and H. Xu, "The role of soot particles in the tribological behavior of engine lubricating oils," Wear, vol. 304, no. 1-2, pp. 152-161, 2013.

[36] V. Eswaraiah, V. Sankaranarayanan, and S. Ramaprabhu, "Graphene-based engine oil nanofluids for tribological applications," ACS Applied Materials \& Interfaces, vol. 3, no. 11, pp. 4221-4227, 2011.

[37] S. Shahnazar, S. Bagheri, and S. B. Hamid, "Enhancing lubricant properties by nanoparticle additives," International Journal of Hydrogen Energy, vol. 41, no. 4, pp. 3153-3170, 2016.

[38] H. Schmutterer, "Properties and potential of natural pesticides from the neem tree, Azadirachta indica," Annual Review of Entomology, vol. 35, no. 1, pp. 271-297

[39] S. Lokanadhan, P. Muthukrishnan, and S. Jeyaraman, "Neem products and their agricultural applications," Journal of Biopesticides, vol. 5, pp. 72-76, 2012.

[40] S. Sanuja, A. Agalya, and M. J. Umapathy, "Synthesis and characterization of zinc oxide-neem oil-chitosan bionanocomposites for food packaging application," International Journal of Biological Macromolecules, vol. 74, pp. 76-84, 2015.

[41] P. Reutemann and A. Ehrlich, "NO: an herbal therapy for alopecia causes dermatitis," Dermatitis: Contact, Atopic, Occupational Drug, vol. 19, no. 3, pp. 12-15, 2008.

[42] D. P. Agrawal, "Medicinal properties of neem: new findings," History of Indian Science, 2001.

[43] K. Girish and B. S. Shankara, "Neem - a green treasure," Electronic Journal of Biology, vol. 4, no. 3, pp. 102-111, 2008.

[44] K. Biswas, I. Chattopadhyay, R. K. Banerjee, and U. Bandyopadhyay, "Biological activities and medicinal properties of neem (Azadirachta indica)," Current Science Bangalore, vol. 82, no. 11, pp. 1336-1345, 2002.

[45] G. Nentwig, "Use of repellents as prophylactic agents," Parasitology Research, vol. 90, no. 1, pp. 40-48, 2003.

[46] A. B. Chaudhari, P. D. Tatiya, R. K. Hedaoo, R. D. Kulkarni, and V. V. Gite, "Polyurethane prepared from neem oil polyester amides for self-healing anticorrosive coatings," Industrial \& Engineering Chemistry Research, vol. 52, no. 30, pp. 10189-10197, 2013.

[47] M. Muhammada, M. Dauda, and B. Bongfa, "Influence of formulated neem seed oil and jatropha curcas seed oil on wire drawing of mild steel and medium carbon steel at elevated temperatures," Jurnal Tribologi, vol. 10, pp. 16-27, 2016. 
[48] Technical Data Sheet, $x G n P^{\star}$ Graphene Nanoplatelets-Grade $C$, XG Sciences, Inc., Michigan, United States, 2012, http://www. xgsciences.com.

[49] F. A. Vidal and A. F. Ávila, "Tribological investigation of nanographite platelets as additive in anti-wear lubricant: a topdown approach," Journal of Tribology, vol. 136, no. 3, p. 031603 , 2014.

[50] X. Ye, L. Ma, Z. Yang, J. Wang, H. Wang, and S. Yang, "Covalent functionalization of fluorinated graphene and subsequent application as water-based lubricant additive," ACS Applied Materials \& Interfaces, vol. 8, no. 11, pp. 7483-7488, 2016.

[51] S. S. Azman, N. W. Zulkifli, H. Masjuki, M. Gulzar, and R. Zahid, "Study of tribological properties of lubricating oil blend added with graphene nanoplatelets," Journal of Materials Research, vol. 31, no. 13, pp. 1932-1938, 2016.

[52] ASTM D 4172-94, "Standard test method for wear preventive characteristics of lubricating fluid (four-ball method)," Annual Book of ASTM Standards, vol. 5, pp. 201-205, ASTM Standards, 2010.

[53] ASTM D 2783-88, "Standard test method for measurement of extreme-pressure properties of lubricating fluids (Four-ball method)," Annual Book of ASTM Standards, vol. 5, pp. 130-137, ASTM Standards, 2002.

[54] X. Wang, X. Xu, and S. U. Choi, "Thermal conductivity of nanoparticle-fluid mixture," Journal of Thermophysics and Heat Transfer, vol. 13, no. 4, pp. 474-480, 1999.

[55] S. J. Asadauskas, R. Kreivaitis, G. Bikulčius, A. Grigucevičiene, and J. Padgurskas, "Tribological effects of $\mathrm{Cu}, \mathrm{Fe}$ and $\mathrm{Zn}$ nanoparticles, suspended in mineral and bio-based oils," Lubrication Science, vol. 28, no. 3, pp. 157-176, 2016.

[56] S. M. Murshed, K. C. Leong, and C. Yang, "Investigations of thermal conductivity and viscosity of nanofluids," International Journal of Thermal Sciences, vol. 47, no. 5, pp. 560-568, 2008.

[57] D. A. Green and R. Lewis, "Effect of soot on oil properties and wear of engine components," Journal of Physics D: Applied Physics, vol. 40, no. 18, p. 5488, 2007.

[58] B. Suresha, G. Hemanth, A. Rakesh, and K. M. Adarsh, "Tribological behaviour of pongamia oil as lubricant with and without halloysite nanotubes using four-ball tester," AIP Conference Proceedings, vol. 2128, no. 1, p. 030011, 2019, AIP Publishing.

[59] H. D. Huang, J. P. Tu, L. P. Gan, and C. Z. Li, "An investigation on tribological properties of graphite nanosheets as oil additive," Wear, vol. 261, no. 2, pp. 140-144, 2006.

[60] A. H. Battez, R. González, D. Felgueroso et al., "Wear prevention behaviour of nanoparticle suspension under extreme pressure conditions," Wear, vol. 263, no. 7-12, pp. 1568-1574, 2007.

[61] T. C. Ing, A. K. M. Rafiq, Y. Azli, and S. Syahrullail, “Tribological behaviour of refined bleached and deodorized palm olein in different loads using a four-ball tribo-tester," Scientia Iranica, vol. 19, no. 6, pp. 1487-1492, 2012.

[62] G. Stachowiak and A. W. Batchelor, "Hydrodynamic lubrication," Engineering Tribology, pp. 103-202, Butterworth-Heinemann, USA, 2013.

[63] E. Hu, X. Hu, T. Liu, L. Fang, K. D. Dearn, and H. Xu, “The role of soot particles in the tribological behaviour of engine lubricating oils," Wear, vol. 304, no. 1-2, pp. 152-161, 2013.

[64] K. G. Binu, B. S. Shenoy, D. S. Rao, and R. Pai, "A variable viscosity approach for the evaluation of load carrying capacity of oil lubricated journal bearing with $\mathrm{TiO}_{2}$ nanoparticles as lubricant additives," Procedia Materials Science, vol. 6, pp. 1051-1067, 2014.

[65] B. Bhushan, Handbook of Micro/Nano Tribology, CRC Press, 1998.

[66] M. J. Furey and J. K. Appeldoorn, "The effect of lubricant viscosity on metallic contact and friction in a sliding system," ASLE Transactions, vol. 5, no. 1, pp. 149-159, 1962.

[67] M. Kozma, "Investigation into the scuffing load capacity of environmentally-friendly lubricating oils," Journal of Synthetic Lubrication, vol. 14, no. 3, pp. 249-258, 1997.

[68] H. Blok, "Wear on wear," Engineering (London), vol. 4502-4503, p. 594, 1952.

[69] S. Syahrullail, S. Kamitani, and A. Shakirin, "Performance of vegetable oil as lubricant in extreme pressure condition," Procedia Engineering, vol. 68, pp. 172-177, 2013.

[70] Y. Xu, Y. Peng, K. D. Dearn, X. Zheng, L. Yao, and X. Hu, "Synergistic lubricating behaviours of graphene and MoS2 dispersed in esterified bio-oil for steel/steel contact," Wear, vol. 342, pp. 297-309, 2015.

[71] W. Zhang, M. Zhou, H. Zhu et al., “Tribological properties of oleic acid-modified graphene as lubricant oil additives," Journal of Physics D: Applied Physics, vol. 44, no. 20, p. 205303, 2011.

[72] E. Omrani, P. L. Menezes, and P. K. Rohatgi, "effect of microand nano-sized carbonous solid lubricants as oil additives in nanofluid on tribological properties," Lubricants, vol. 7, no. 3, p. 25, 2019.

[73] I. M. Feng, "Metal transfer and wear," Journal of Applied Physics, vol. 23, no. 9, pp. 1011-1019, 1952.

[74] N. W. Zulkifli, M. A. Kalam, H. H. Masjuki, M. Shahabuddin, and R. Yunus, "Wear prevention characteristics of a palm oilbased TMP (trimethylolpropane) ester as an engine lubricant," Energy, vol. 54, pp. 167-173, 2013. 